NBER WORKING PAPER SERIES

THE EMPIRICS OF MONETARY POLICY RULES IN OPEN ECONOMIES

Richard H. Clarida

Working Paper 8603

http://www.nber.org/papers/w8603

NATIONAL BUREAU OF ECONOMIC RESEARCH

1050 Massachusetts Avenue

Cambridge, MA 02138

November 2001

This paper was prepared as a Keynote Address for the ESRC Conference on the Future of Macroeconomics held at the Bank of England Conference Center on April 14, 2000. The views expressed herein are those of the author and not necessarily those of the National Bureau of Economic Research.

(C) 2001 by Richard H. Clarida. All rights reserved. Short sections of text, not to exceed two paragraphs, may be quoted without explicit permission provided that full credit, including $\mathbb{C}$ notice, is given to the source. 
The Empirics of Monetary Policy Rules in Open Economies

Richard H. Clarida

NBER Working Paper No. 8603

November 2001

JEL No. F31

\begin{abstract}
This paper was prepared as a Keynote Address for the ESRC Conference on the Future of Macroeconomics held at the Bank of England Conference Center on April 14, 2000. It uses the empirical framework for formulating and estimating forward looking monetary policy rules developed in Clarida ,Gali, Gertler (1998; 1999; 2000;2001) and Clarida (2000) to assess what we know , don't know, and can't tell about monetary policy making in an open economy with an (implicit) inflation target. Among the issues discussed are: the relationship between structural VAR models of monetary policy and exchange rates and estimates of forward looking Taylor rules; the relationship between inflation targeting and leaning against the (exchange rate) wind; why central bankers are averse to even wide - band target zones; quantifying that stresses and costs of a one size fits all monetary policy for the members of a monetary union or currency bloc.
\end{abstract}

\author{
Richard Clarida \\ NBER and Columbia University \\ Room 1014 \\ 420 W. 118th Street \\ New York, NY 10027 \\ rhc2@columbia.edu
}




\section{THE EMPIRICS OF MONETARY POLICY RULES IN OPEN ECONOMIES}

\section{Richard H. Clarida}

\section{Columbia University}

\section{The National Bureau of Economic Research}

\section{$\underline{1 . \text { Introduction and Motivation }}$}

The line of research that Mark Gertler and Jordi Gali and I have been working on for the past several years was initially motivated by a question and, later, a realization. The question was how to use the tool of choice in empirical macroeconomics, the structural VAR, to understand why some central banks (such as the Fed and the Bundesbank) were more successful than others during the 1980s and 1990s in maintaining low and stable inflation.

A structural VAR can be used to trace through the dynamic effects of shocks to monetary policy on such variables as inflation, output, and the exchange rate and to estimate the importance monetary policy shocks in explaining particular episodes in macroeconomic history. This strategy has been employed with much success by Sims (1980), Bernanke and Blinder (1992), and Christiano, Eichenbaum Evans (1994) to study the US economy, and to study the effects of monetary policy on exchange rates by Eichenbaum and Evans (1994). When Clarida and Gertler (1997) applied this approach to Germany, they found similar results. A positive, structural shock to the policy instrument, the day-to-day 
interest rate, resulted in a decline in production and sales, an appreciation of the DM, and eventually a slowdown in inflation.

Empirical results of this sort, while useful and interesting in themselves, are not particularly informative with respect to actually explaining the success of central banks at reducing and maintaining low and stable inflation. To answer such a question, we realized that it is necessary to take a stand on the systematic component of monetary policy, and not just identify the structural shocks to monetary policy (which is all that the structural VAR approach requires). The structural VAR restrictions provided estimates of the contemporaneous relationship between surprises in the policy instrument and surprises in other macro variables such as inflation, production, sales, commodity prices, the US interest rates, and the exchange rate, thus yielding a central bank reaction function in surprises. The question remained: how to tease out of the VAR, or more precisely to tease out of the VAR equation for the short term interest rate, a parsimonious and empirically refutable interpretation of the systematic response of the policy instrument to all lagged as well as current information about the macro variables included in the VAR.

One possibility is to calculate from the VAR dynamic impulse responses as well as a real time historical decomposition of the policy instrument so as to characterize the average dynamic response of monetary policy to various macro shocks as well as to estimate the relative importance of these shocks in explaining 
the historical behavior of short term interest rates, the presumed instrument of policy. Calculations such as these yield results that are straightforward to interpret, at least as far as they go. For example, the dynamics of German short term interest rates - the presumed policy instrument of the Bundesbank - appeared during the 1980 s and 1990 s to be driven by swings in the $\mathrm{DM} / \$$ exchange rate, US interest rates, commodity prices, and the business cycle in German output (Clarida-Gertler (1997)). A weak (strong) DM/\$ exchange rate, high (low) US interest rates, or surges (declines) in commodity prices tended to be associated with tight (easy) German monetary policy while cyclical slumps (booms) in German output tended to be associated with easy (tight) monetary policy.

Although these findings such as these are suggestive of a policy of "leaning against the wind", they don't provide the parsimonious characterization of VAR interest rate equation one would need to describe the systematic part of policy. Moreover, the impulse responses and historical decompositions that could be derived from the VAR cannot be used to sort through some interesting hypotheses about central bank behavior that one might wish to examine. For example, it appears from VAR evidence that central banks raise interest rates when output is booming, and cut rates when output is slumping. Is this because the central bank seeks only to stabilize inflation but reacts to the output gap because it is a forecaster of future inflation? 
To provide a parsimonious interpretation of monetary policy that is consistent with the VAR evidence for Germany and other countries, we were lead to hypothesize that central banks rely on a forward looking Taylor rule

$$
r_{t}^{*}=r r+\pi^{*}+\beta E\left[\pi_{t+n}-\pi^{*} \mid \Omega_{t}\right]+\gamma E\left[x_{t} \mid \Omega_{t}\right]+v_{t}
$$

as a guide for setting short term interest rates (McNees (1986) hypothesized a forward looking Fed reaction function and used data on internal Fed forecasts to evaluate this model). Here $r_{t}^{*}$ is the reference (or target) level for the policy instrument, $\pi^{*}$ is the (assumed constant) inflation target, $x_{t}$ is the output gap, $v_{t}$ is a structural shock to monetary policy, and $r r$ is the (assumed constant) equilibrium real interest rate. We thought ex ante (before we ran any regressions) that this was a potentially attractive hypothesis. It to us seemed able to resolve the dissatisfaction that we, and we suspect many others, had with a large literature from the 1960s and 1970s that wrote down and estimated a wide variety of central bank reactions functions with little if any attempt to justify the exclusion of variables or to provide a robust structural interpretation for the variables that were included.

\section{Forward Looking Taylor Rules and Structural VARS}

To illustrate some key points, it will be useful to consider a simple example. Let $z_{t}=\left[y_{t}, \pi_{t}, r_{t}, e_{t}\right]$ and suppose, as in Eichenbaum and Evans (1994), that the short term interest rate is the policy instrument, and that the exchange rate, $e_{t}$, is 
ordered last. The structural VAR (with A lower triangular) representation is written

$$
A z_{t}=B z_{t-1}+\varepsilon_{t}
$$

and the reduced form VAR

$$
z_{t}=A^{-1} B z_{t-1}+u_{t}
$$

The the interest rate equation in the structural VAR is given by

$$
r_{t}=-A_{31} x_{t}-A_{32} \pi_{t}+B_{31} x_{t-1}+B_{32} \pi_{t-1}+B_{33} r_{t-1}+B_{34} e_{t-1}+\varepsilon_{r, t}
$$

Now, the simplest FLRT model can be written as

$$
r_{t}=\beta E\left[\pi_{t+n} \mid \Omega_{t}\right]+\gamma E\left[x_{t} \mid \Omega_{t}\right]+v_{t}
$$

Project $\pi_{t, n}$ on $\underline{\Omega}_{t}$, where $\underline{\Omega}_{t}=\left[x_{t}, \pi_{t}, z_{t-1}\right]$.

$$
E \pi_{t, n} \mid \underline{\Omega}_{t}=\alpha_{1} x_{t}+\alpha_{2} \pi_{t}+\theta_{1} x_{t-1}+\theta_{2} \pi_{t-1}+\theta_{3} r_{t-1}+\theta_{4} e_{t-1}
$$

Substituting, we can write $r_{t}$ as

$r_{t}=\beta\left[\alpha_{1} x_{t}+\alpha_{2} \pi_{t}+\theta_{1} x_{t-1}+\theta_{2} \pi_{t-1}+\theta_{3} r_{t-1}+\theta_{4} e_{t-1}\right]+\gamma x_{t}+v_{t}+\omega_{t}$

where $\omega_{\mathrm{t}}=\beta E\left[\pi_{t+n} \mid \Omega_{t}\right]-\beta E\left[\pi_{t+n} \mid \underline{\Omega}_{t}\right]$.

Thus we can think of the FLTR hypothesis as placing cross-equation restrictions on a bivariate system comprised of (a) a projection of realized future inflation on $\underline{\Omega}_{t}$ (b) our forward looking Taylor rule which embodies these projection coefficients as well as the parameters $\beta$ and $\gamma$. We note that since $\underline{\Omega}_{t} \subseteq$ $\Omega_{t}$, both $v_{t}$ and $\omega_{t}$ are orthogonal to $\underline{\Omega}_{t}$ (Mishkin (1982) proposed this idea to test the hypothesis that only unanticipated money influences output). It follows that the FLTR places overidentifying restrictions on the data. The bivariate system 
comprised of projecting inflation and the interest rate on $\underline{\Omega}_{t}$ has twelve orthogonality conditions (since there are six instruments and two equations) but only eight parameters (the six coefficients in the inflation projection and the two FLTR parameters $\beta$ and $\gamma$ ) so there are four overidentifying restrictions. Note that in the special case in which the VAR information set corresponds to the central bank's, $\underline{\Omega}_{t}=\Omega_{t}$ and we can interpret $\varepsilon_{r, t}=v_{t}$ as the structural shock to monetary policy. However in general the composite error term will also contain the difference between expected inflation conditional on the full information set and expected inflation conditional on the VAR information set. The point is well known but is worth repeating: in general, for the structural VAR disturbance $\varepsilon_{r, t}$ to represent a shock to monetary policy icy, we need not only to get "the order right" but also to get "information set right". This point is often made in the context of trying to resolve the 'price puzzle' evident in many VAR models by expanding the number of variables included so as to pick up shifts in expected inflation that drive both interest rates and actual inflation higher at the same time.

Comparing coefficients, the FLTR places the following restrictions on an Eichenbaum - Evans type SVAR interest rate equation:

$$
\begin{aligned}
-A_{31} & =\beta \alpha_{1}+\gamma \\
-A_{32} & =\beta \alpha_{2} \\
B_{31} & =\beta \theta_{1} \\
B_{32} & =\beta \theta_{2}
\end{aligned}
$$




$$
\begin{aligned}
& B_{33}=\beta \theta_{3} \\
& B_{34}=\beta \theta_{4}
\end{aligned}
$$

From these equations, we see the relationship between the exact identification the structural VAR shock $\varepsilon_{r, t}$ to monetary policy that is achieved by assuming a triangular A matrix, and the overidentification of the monetary policy reaction function parameters $\beta$ and $\gamma$-parameters that describe the systematic as opposed to the surprising part of policy - that is achieved by hypothesizing and testing that the central bank pursues a forward looking Taylor rule. Under the assumption that A is lower triangular (and that $\underline{\Omega}$ t captures the central bank's information set), the $\mathrm{A}$ and $\mathrm{B}$ matrices are uniquely recovered from the reduced form VAR as is the vector $\varepsilon_{\mathrm{t}}$ of structural disturbances. Under the hypothesis that the central bank pursues a forward looking Taylor rule, the preceding system represents six equations in two unknowns $\beta$ and $\gamma$, since the $\alpha$ and $\theta$ are not free but are restricted by hypothesis that the central bank sets policy based upon an inflation (and perhaps also) output gap forecast. This is the key empirical implication of inflation forecast targeting (Clarida-Gali-Gertler (2000)).

The SVAR literature can tell us about the effects of monetary policy shocks on the rest of the economy and on the exchange rate, but it takes no stand on interpreting the systematic part of monetary policy. Moreover, unlike much of the SVAR literature, the FLTR hypothesis places testable restrictions on the data (Clarida-Gali-Gertler (2000)). One simply uses GMM to estimate the FLTR, 
instrumenting realized inflation and output with lagged - and perhaps a subset of current - macro variables.

We note a basic but essential point about our approach: it does not require that we know the central bank's information set. We can still recover estimates of the structural parameters $\beta$ and $\gamma$ without having to assume that $\underline{\Omega}_{t}=\Omega_{t}$. By the law of iterated expectations, $\left(E \pi_{t, n}\left|\Omega_{t}-E \pi_{t, n}\right| \underline{\Omega}_{t}\right)$ will be orthogonal to $\underline{\Omega}_{t}$. Our theory has empirical content because it assumes, in common with the SVAR literature, that $v_{\mathrm{t}}$ is orthogonal to $\underline{\Omega}_{t}$.

We suspect that one reason the CGG approach has been popular is it addresses, in a parsimonious, testable fashion, the "kitchen sink" problem that many people have with VAR models (and, it should be noted, with the early literature on central bank reaction functions pioneered by Dewald and Johnson (1963)). VAR models (and the 'first generation' reaction function specifications) find that a collection of $\mathrm{n}$ variables lagged $\mathrm{q}$ times can account for the dynamic behavior of the short term interest rate. But why? Since Sims' classic paper in the early 1980s, economists have been aware of the danger of imposing exclusion restrictions on lagged endogenous variables precisely because they are likely to enter the optimal decision rules of rational agents who base their actions in part on forecasts of future events. The FLTR explains the VAR interest rate equation as the outcome of monetary policy decision rule which is based on a forecast of target variables that enter the central bank's objective function (Clarida-Gali- 
Gertler $(1999 ; 2001)$. Or as we have described in other presentations, according to the FLTR, 'central banks look at everything but only to the extent that 'everything' is useful in forecasting inflation and possibly output'.

\section{$\underline{\text { 3. Are Central Banks Exchange Rate Targeters? }}$}

Of course, one of things that central banks look at is the exchange rate. For example, the Bank of England's Inflation Report specifically reviews how the current level of the pound and the forecasted path for the pound will impact on the inflation forecast. Also, as Clarida and Gertler point out, in the 1970s, 1980s, and 1990s, the Bundesbank's Monthly Reports made frequent mention of why fluctuations in the DM exchange rate would be factored into monetary policy, with a weak DM indicating possible inflationary pressures and a strong DM indicating a contraction in aggregate demand. Clarida and Gertler reported VAR evidence the day-to-day money rate, the instrument of Bundesbank monetary policy, did indeed respond to the DM in the way the Bundesbank described. G3 central banks, the Bank of England, and the Bank of Canada typically do not admit to having a target for the exchange rate, but from the VAR evidence alone, it is impossible to tell.

The CGG approach can be used to test the hypothesis that the exchange rate influences the policy instrument because it is an indicator of future inflation and output trends against the alternative that the exchange rate influences the policy 
instrument because it is a target of monetary policy. Recall our equation for the simple FLTR

$$
r_{t}=\beta\left[\alpha_{1} x_{t}+\alpha_{2} \pi_{t}+\theta_{1} x_{t-1}+\theta_{2} \pi_{t-1}+\theta_{3} r_{t-1}+\theta_{4} e_{t-1}\right]+\not x_{t}+v_{t}+\omega_{t}
$$

where the $\alpha$ 's and $\theta$ 's are the coefficients from the projection of realized inflation on the macro instruments. This equation embodies the hypothesis that the exchange rate influences the policy instrument only because it is an indicator of future inflation. We have

$$
\partial r_{t} / \partial e_{t-1}=\beta \theta_{4}
$$

The response of the interest rate to the exchange rate is the product of the response of the interest rate to expected inflation and the response of the inflation forecast to an exchange rate depreciation. Consider the alternative hypothesis that the exchange rate, along with inflation and the output gap, is a target of monetary policy that directly enters the monetary policy rule

$$
r_{t}=\beta E\left[\pi_{t+n} \mid \Omega_{t}\right]+\gamma E\left[x_{t} \mid \Omega_{t}\right]+\xi e_{t-1}+v_{t}
$$

This generalization to FLTR implies, in our example, that

$$
r_{t}=\beta\left[\alpha_{1} x_{t}+\alpha_{2} \pi_{t}+\theta_{1} x_{t-1}+\theta_{2} \pi_{t-1}+\theta_{3} r_{t-1}+\theta_{4} e_{t-1}\right]+\not x_{t}+\xi e_{t-1}+v_{t}+\omega_{t}
$$

There are now FLTR parameters to estimate $-\beta, \gamma$, and $\xi$ - with six instruments so that there are three overidentifying restrictions. For this more general model (which encompasses the benchmark specification) we have

$$
\partial r_{t} / \partial e_{t-1}=\xi+\beta \theta_{4}
$$


The response of the interest rate to the exchange rate now includes the direct 'leaning against the wind' channel through which the central bank adjusts the interest rate so that the $(\log )$ exchange rate does not wander too far away from the target level (here normalized to 0 ). This hypothesis can be tested by computing the t-ratio for the estimated $\xi$ coefficient.

Clarida-Gali-Gertler (1998) report in Tables 1,2, and 3 that a forward looking Taylor rule, suitably modified to capture the interest rate smoothing behavior that central banks are observed to follow (Goodfriend (1991)) does a good job of accounting for the setting of short term nominal interest rates by the Bundesbank, the Bank of Japan, and the Federal Reserve during the 1980s and 1990s. The parameter estimates of the estimated reaction function for each G3 central bank are quite sensible, and in all cases indicate that these central banks have tended to raise nominal interest rates aggressively in response to information indicating a rise in expected inflation. The estimated reaction functions also imply that these central banks seek to lower the real and nominal interest rates when output is below a simple measure capacity even when expected inflation is on target. That is, for the G3 central banks, the output gap appears to be a target of monetary policy and not just an indicator of future inflation trends.

Although CGG (1998) could not reject the overidentifying restrictions implied by the hypothesis that the G3 central banks have followed forward looking Taylor rules, the paper also investigates whether or not the Bundesbank and the 
Bank of Japan have allowed international considerations to influence the setting of short term interest rates. The papers finds that deviations from purchasing power parity of the nominal exchange rate with the dollar had statistically significant but economically small effects of the expected sign on the setting of short term interest rates by the Bank of Japan and the Bundesbank.

\section{If Not Why Not?}

Thus, there is evidence that the Bundesbank and the Bank of Japan have historically placed at least some weight on stabilizing the exchange relative to a PPP path that incorporates inflation differentials (McKinnon (1995) has made this observation in his criticism of Japan's monetary policy during the 1990s). Yet these central banks, the Fed, the ECB, and since 1992, the Bank of England have been quick to reject calls that they go further and announce (and defend) formal target zones for their currencies, even zones with very wide (plus or minus $10 \%$ ) bands. The theory of target zones is clear: if a zone is credible, there can be, especially with wide bands, a great deal of latitude for countries to pursue monetary policies tailored to domestic macroeconomic conditions. Moreover, this latitude does not, under a credible commitment to defend the zonal boundaries, come at the expense of stabilizing intraband exchange rate volatility relative to the equilibrium that would prevail in the absence of the zone.

One explanation for the reluctance of the G3 countries to embrace exchange rate targeting more formally is that, even if such commitments could be made fully 
credible, the reduction intraband exchange rate volatility that could be achieved would be modest given the width of the band that policymakers would accept. Thus, even if a band were credible, a very wide band would do little to stabilize expectations and to diminish intraband exchange rate volatility. The evidence, as reviewed in Clarida (2000), indicates that the reduction in volatility that has been observed in actual successful target zone arrangements (i.e. the Dutch and French success in keeping their currencies within narrow bands of parity with the DM during the last dozen years of the EMS) derives, in a significant way, from the dedication of monetary policy to the task of keeping, via nonsterlized intraband interventions, the exchange rate near the central parity - at the expense of other macroeconomic objectives - and not, primarily from stabilizing expectations.

Clarida (2000) discusses another possible explanation for reluctance of the G3 countries to embrace exchange rate targeting more formally. Suppose an explicit, wide band target zone when announced is not credible and that the markets expect 'business as usual'. The markets expect the same monetary policies that prevailed before the announcement to continue after the announcement of the zone. Suppose that this expectation is, at least initially, rational so that these policies do continue until the exchange rate first reaches a zonal boundary (after all, the point of adopting a wide band is to provide central banks with the leeway to pursue policies that incorporate objectives in addition to exchange rate stability). It is only at this date, and not before, that the markets can 
learn anything about the credibility of the target zone commitment. Whether or not they do learn anything on this date is another matter. The monetary policy that is called for to meet domestic objectives such as maintaining low but positive inflation and keeping output at potential may also be consistent with reversing a apparent 'misalignments' of the exchange rate relative to the fundamentals.

If this is the case, then as the exchange rate approaches the zonal boundary, the markets will learn nothing about the commitment to the target zone, and expectations will not be stabilized. Now at some point, the zonal boundaries will be approached and defending them will require that monetary policy be devoted to this purpose to the exclusion of domestic objectives. It is at this date, and only at this date, that the markets will learn something about the target zone commitment. But even after this initial observation, it may take not just one, but several, such observations (separated perhaps by several years) before the zone has full credibility, and before this credibility delivers the intraband exchange rate stability predicted by the theory. Thus, building up credibility for a wide band target zone may take longer - much longer - than might be expected precisely because of the leeway for monetary policy afforded by the choice of the wide band.

To appreciate why it might be difficult for the markets to disentangle 'status quo' monetary policy from a commitment to a wide band target zone, consider again the interest rate equation from an Eichenbaum-Evans style VAR which would be estimated from the behavior of a central bank following a FLTR 


$$
r_{t}=\beta\left[\alpha_{1} x_{t}+\alpha_{2} \pi_{t}+\theta_{1} x_{t-1}+\theta_{2} \pi_{t-1}+\theta_{3} r_{t-1}+\theta_{4} e_{t-1}\right]+\gamma x_{t}+v_{t}+\omega_{t}
$$

Now what sort of relationship between the exchange rate and the short term interest rate would be expected to result from such a status quo monetary policy? This depends on the sign of $\theta_{4}$. Under plausible circumstances, we expect $\theta_{4}$ to be positive, and there is support for this in the data. This means that when a currency depreciates (relative to, say, PPP), expected inflation tends to rise. The important implication of all this is that, even though if a central bank is not targeting the exchange rate, the bank's desire to stabilize the inflation forecast will lead it to raise nominal and real interest rates when the currency is weakening, and to lower nominal and real interest rates when the currency is strengthening . This reaction, in turn, will tend to appreciate the exchange rate when it is weak and to weaken the exchange rate when it is strong (relative to the PPP benchmark). Thus, in practice, a monetary policy aimed at achieving only domestic objectives may also serve to stabilize the exchange rate (see Wadhwani (1999) for an elaboration of this point as it applies to the inflation targeting strategy of the Bank of England), and thus be difficult to distinguish from a policy of maintaining the exchange rate within a band. 


\section{$\underline{\text { 5. Does One Size Fit All? }}$}

The FLTR hypothesis places testable restrictions on the data (and implicitly on VAR models of monetary policy) and implies that a small number of parameters are sufficient to describe the positive economics of monetary policy. Clarida-Gali-Gertler (1998) go further and suggest that the parameters from an estimated FLTR can also be used quantify and interpret the stresses and strains that can and do emerge in fixed exchange rate systems (such as the EMS), in monetary unions (such as EMU), and under currency boards (as are currently in place in Hong Kong and Argentina). Although these systems differ in many ways, they share some essential features: a common monetary policy for a collection of countries that agree on a common inflation target but that are subject to idiosyncratic shocks that can push their business cycles and inflation rates out of phase. Clearly countries perceive and derive substantial benefits from these arrangements, but such commitments can also entail costs. Among these costs are (1) the inability to lower interest rates (real and nominal) when the home country is recession and to be forced to rely entirely on a gradual gain in competitiveness to restore internal balance; and (2) the inability to raise interest rates (real and nominal) when home country inflation surges above the common inflation target and to be forced to rely entirely on a loss of competitiveness to restore internal balance. 
CGG propose that these costs can be quantified in the following way. Compute for each country in the monetary arrangement a (counterfactual) Taylor rule path for the domestic short term interest rate based upon that country's expected inflation and output gap and the estimated (or assumed) Taylor rule weights for the central bank that is setting monetary policy for the group. This counterfactual path for the nominal interest rate does not necessarily represent an alternative for monetary policy that is actually available to the country, given its objectives for inflation, output, and the exchange rate. Rather, the counterfactual path can be compared to the realized path of interest rates in each country to quantity the costs that are incurred by the commitment to a monetary regime that ties the hands of domestic monetary policy.

In Clarida-Gali-Gertler (1998), this approach was used to study the collapse of the EMS in 1992 - 1993. For France and Italy, CGG found a positive gap between French and Italian interest rates and their counterfactual Taylor rule counterparts that widened steadily and substantially throughout 1991-1992, resulting in Italian interest rates that were 1000 basis points higher than their counterfactual Taylor rule counterpart in September 1992 (when Italy withdrew from the ERM) and French interest rates that were 800 basis points higher than their Taylor rule counterpart on the eve of the August 1993 're-design' of the ERM (see Buiter-Corsetti-Pessenti (1996) for all the details). For Britain, when it entered the ERM in October 1990, interest rates were in line with the Taylor rule 
"counterfactual". As was the case for France and Italy, a positive gap between the British interest rate and the counterfactual Taylor rule counterpart began to emerge and widened steadily and substantially throughout 1991-1992, resulting in British interest rates that were nearly 400 basis points higher than their counterfactual Taylor rule counterpart in September 1992 (when Britain chose to drop out of the ERM and adopt inflation targeting). Thus, during the last years of the ERM, the costs of the 'one size fits all' monetary policy of the Bundesbank for the other countries in the system was estimated to be substantial, ranging from 400 basis points in Britain to 1000 basis points in Italy. CGG refer to this difference between actual interest rate in country $j$ and the counterfactual FLTR interest rate as a stress indicator.

$$
\text { stress }_{j, t}=r_{j, t}-\beta E\left[\pi_{j, t+n} \mid \Omega_{t}\right]-\gamma E\left[x_{j, t} \mid \Omega_{t}\right]
$$

The motivation for defining stress in this way derives from the rationale that policymakers themselves often use, after the fact, to explain their unwillingness to hang on to an exchange rate arrangement that ties the hands of monetary policy during an economic downturn. Here is a quote from the Bank of England in November 1992

Against a backdrop of sluggish activity and stable or falling inflation, a number of countries in Europe have experienced a growing conflict between the monetary policy required to maintain the exchange rate, and the policy that would be appropriate given domestic cyclical conditions. In a number of cases, nominal interest rates might have been lower but for the ERM. This was particularly the case for those countries which were . . in a different cyclical position. 
The CGG stress indicator is a simple to compute - and easy to understand - way to gauge how much different interest rates might be but for been but for a binding a commitment to an exchange rate arrangement, monetary union, or currency board.

Stress can be decomposed in an interesting way. It is the sum of three terms: ( i ) stress in the policy of the central bank setting interest rates for the group (e.g., the Bundesbank in the case of the EMS, the ECB in the case of EMU, and the US in the case of Hong Kong and Argentina); (ii) an index (using Taylor Rule weights) of the divergence between inflation and output across countries (i.e. between the EMU country under study and EMU wide averages); (iii) and the interest differential between the country under study and the interest rate set by the central bank running monetary policy for the group ( a measure of the credibility of the commitment to the regime). In symbols we have

$$
\operatorname{stress}_{j, c, t} \equiv \operatorname{stress}_{c, t}+\left[\beta\left(\pi_{c, t}-\pi_{j, t}\right)+\gamma\left(x_{c, t}-x_{j, t}\right)\right]+R_{j, t}-R_{c, t}
$$

According to this decomposition, the cost of forgoing an independent monetary policy increases with the divergence between home and average inflation rates and output gaps, the interest differential, and the stance of monetary policy (relative to the Taylor rule benchmark) by the central bank running monetary policy for the group. 


\section{Conclusion}

This paper has used the empirical framework developed in Clarida ,Gali, Gertler $(1998 ; 1999 ; 2000)$ and Clarida $(2000)$ to assess what we know , don't know, and can't tell about monetary policy making in an open economy with an (implicit) inflation target. We have shown how our approach can be used to interpret structural VAR models of monetary policy and exchange rates and have provided a novel explanation for why central bankers who currently set policy based on inflation forecast might be averse to even wide - band target zones. Finally, we suggest a way to quantify and decompose the stresses and costs of a one size fits all monetary policy for the members of a monetary union or currency bloc. 


\section{References}

Bernanke, B. and A. Blinder, "The Federal Funds Rate and the Channels of Monetary Transmission," American Economic Review, September 1992, 901-921.

Buiter, W., G. Corsetti, and P. Pesenti, "Interpreting the ERM Crisis," CEPR Discussion Paper No. 1466, April 1997.

Christiano, L. , M. Eichenbaum, and C. Evans, "Identification and the Effects of Monetary Policy Shocks,” FRB Chicago Working Paper 94-7, May 1994.

Clarida, R., "G3 Exchange Rate Relationships: A Recap of the Record and a Review of Proposals for Change," Princeton Essays in International Finance, September 2000.

Clarida, R. and M. Gertler, "How the Bundesbank Conducts Monetary Policy," in C. Romer and D. Romer, eds., Reducing Inflation, Chicago: University of Chicago Press, 1997.

Clarida, R., J. Gali and M. Gertler, "Monetary Policy Rules in Practice: Some International Evidence,” European Economic Review, June 1998.

Clarida, R., J. Gali and M. Gertler, "The Science of Monetary Policy: A New Keynesian Perspective," Journal of Economic Literature, December 1999.

Clarida, R., J. Gali and M. Gertler, "Monetary Policy Rules and Macroeconomic Stability: Theory and Evidence," Quarterly Journal of Economics, January 2000.

Clarida, R., J. Gali and M. Gertler, "Optimal Monetary Policy in Closed vs Open Economies: An Integrated Approach," American Economic Review Papers and Proceedings, May 2001.

Dewald, W. and H. Johnson, "An Objective Analysis of the Objectives of Monetary Policy," in Banking and Monetary Studies, D, Carson, ed., Richard D. Irwin, 1963.

Eichenbaum, M. and C. Evans, "Some Empirical Evidence on the Effects of Monetary Policy Shocks on Exchange Rates," Quarterly Journal of Economics, (110) 1995.

Goodfriend, M. "Interest Rates and the Conduct of Monetary Policy," CarnegieRochester Conference Series on Monetary Policy (34), 1991. 
Mishkin, F., "Does Anticipated Monetary Policy Matter? An Econometric Evaluation," Journal of Political Economy, February 1982.

McKinnon, R., The Rules of the Game, MIT Press, 1995.

McNees, S., "Modeling the Fed: A Forward Looking Monetary Policy Reaction Function" New England Economic Review, 1986.

Sims, C., "Macroeconomics and Reality," Econometrica, 48, 1980, 1 - 48.

Wadhwani, S., "Currency Puzzles,” mimeo, Bank of England, September 1999. 
